\title{
Dietary carbohydrates: role of quality and quantity in chronic disease
}

\section{David S Ludwig and colleagues examine the links between different types of carbohydrate and health}

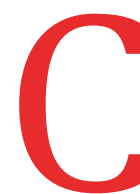

arbohydrate is the only macronutrient with no established minimum requirement. Although many populations have thrived with carbohydrate as their main source of energy, others have done so with few if any carbohydrate containing foods throughout much of the year (eg, traditional diets of the Inuit, Laplanders, and some Native Americans). ${ }^{12}$ If carbohydrate is not necessary for survival, it raises questions about the amount and type of this macronutrient needed for optimal health, longevity, and sustainability. This review focuses on these current controversies, with special focus on obesity, diabetes, cardiovascular disease, cancer, and early death.

\section{Role of carbohydrate consumption in human development}

The large brain of modern humans is energetically expensive, requiring a disproportionate share of dietary energy compared with that of other primates. The first hunting and gathering societies were characterised by greater consumption of not only animal foods but also plant foods with greater carbohydrate availability than leaves-including ripe fruit, honey, and eventually cooked starchy foods. ${ }^{34}$ The higher nutrient and energy density of this diet allowed for evolution of a smaller gastrointestinal tract, offsetting the energy demands of the brain. ${ }^{5}$

\section{KEY MESSAGES}

- Human populations have thrived on diets with widely varying carbohydrate content

- Carbohydrate quality has a major influence on risk for numerous chronic diseases

- Replacing processed carbohydrates with unprocessed carbohydrates or healthy fats would greatly benefit public health

- The benefit of replacing fructose containing sugars with other processed carbohydrates is unclear

- People with severe insulin resistance or diabetes may benefit from reduction of total carbohydrate intake
As a result of selective pressures related to dietary changes, two major gene adaptations occurred affecting carbohydrate digestion: average salivary amylase gene copy number (AMY1) increased more than threefold, with substantial variation among populations related to starch consumption ${ }^{6}$; and lactase persistence into adulthood developed in multiple geographically distinct populations, facilitating digestion of the milk sugar lactose. ${ }^{7}$ After our transition to an agrarian lifestyle in the Neolithic period, beginning 12000 to 14000 years ago, total carbohydrate intake increased substantially as grains became a dietary staple, but archaeological evidence shows that diet related problems also emerged, including endemic nutrient deficiencies, a decrease in mean height, and dental caries. $^{8-10}$

\section{Relation between carbohydrate types and health outcomes}

Carbohydrates are formally defined as containing carbon, hydrogen, and oxygen in the ratio of $1: 2: 1$. In practice, dietary carbohydrates comprise compounds that can be digested or metabolically transformed directly into glucose, or that undergo oxidation into pyruvate, including some sugar alcohols (eg, sorbitol). Several systems for classifying carbohydrates have been in use, with varying relevance to health outcomes.

\section{Chain length}

Carbohydrates can be categorised according to degree of polymerisation into monosaccharides (monomers), disaccharides, oligosaccharides, and polysaccharides (starch). Conventionally, carbohydrate polymer length is believed to determine the rate of digestion and absorption, and therefore the rise in blood glucose after eating. People with diabetes were therefore instructed to avoid sugars and emphasise starchy foods. ${ }^{11}$ However, research beginning 50 years ago showed no meaningful relation between carbohydrate chain length and postprandial glycaemia or insulinaemia. ${ }^{12}{ }^{13}$ Modern starchy foods such as bread, potatoes, and rice raise blood glucose and insulin substantially more than some high sugar foods (eg, whole fruits). ${ }^{14}$ By contrast, some traditionally consumed starches (legumes, whole kernel grains, pasta, long fermentation sourdough bread) release glucose more slowly because the starch is protected from digestion by the food matrix (gelatinised) or because the presence of organic acids slows gastric emptying.

\section{Glycaemic index and glycaemic load}

Although carbohydrates are the only food constituents that directly increase blood glucose (the main determinant of insulin secretion), population studies suggest that the total amount of carbohydrate as a percentage of dietary energy is less important than the carbohydrate type for risk of chronic disease. Refined grains, potatoes, and sugar sweetened beverages are associated with increased risk, ${ }^{15}$ whereas minimally processed grains, legumes, and whole fruits are associated with reduced risk. ${ }^{16}$ This distinction may be explained partly by differences in how specific carbohydrates affect postprandial hyperglycaemia and hyperinsulinaema, which are causally related to the development of type 2 diabetes, coronary heart disease, and perhaps obesity. ${ }^{17}$

Two empirical metrics have been introduced to rank foods according to effects on blood glucose: glycaemic index (GI) and glycaemic load (GL) (table 1). The GI compares foods based on a standardised amount of available carbohydrate. Glycaemic load (GI multiplied by the amount of carbohydrate in a typical serving) allows the glycaemic effect of foods, meals, and whole diets to be compared as realistically consumed, and it has been shown to be a better predictor of glycaemic response than the amounts of carbohydrate, protein, and fat in food. ${ }^{18}$ Prospective observational studies have reported that higher energy adjusted GI or total GL is an independent risk factor for type 2 diabetes in men and women ${ }^{19}$; cardiovascular morbidity and mortality, including stroke, in women ${ }^{20-22}$; and certain types of cancers in both sexes, ${ }^{2324}$ though some have questioned the strength and consistency of these findings. ${ }^{25}$

\section{Fibre and resistant starch}

Fibre or non-starch polysaccharide is plant carbohydrate that is not digestible by human enzymes. Fibre and resistant starch provide, to varying degrees, substrate for 


\begin{tabular}{|c|c|c|c|c|}
\hline Food & Serving size (g) & $\begin{array}{l}\text { Available carbohydrate* } \\
\text { (g) per serving }\end{array}$ & Glycaemic indext & Glycaemic load \\
\hline Rice, jasmine, boiled & 120 & 32 & 86 & 28 \\
\hline Instant oat porridge/oatmeal & 250 & 26 & 79 & 21 \\
\hline Rice, basmati, boiled & 120 & 30 & 57 & 17 \\
\hline Potato, boiled & 150 & 20 & 78 & 16 \\
\hline Breakfast cereal, flaked & 30 & 22 & 72 & 16 \\
\hline Pasta, white or brown, boiled & 120 & 31 & 49 & 15 \\
\hline Bread, white or brown & 40 & 19 & 75 & 14 \\
\hline Traditional oat porridge & 250 & 24 & 55 & 13 \\
\hline Fruitjuice & $250 \mathrm{~mL}$ & 24 & 50 & 12 \\
\hline Fruit, tropical & 120 & 16 & 58 & 9 \\
\hline Barley, boiled & 120 & 34 & 28 & 9 \\
\hline Bread, wholemeal & 40 & 13 & 54 & 7 \\
\hline Legumes, boiled & 150 & 22 & 31 & 7 \\
\hline Fruit, temperate & 120 & 14 & 42 & 6 \\
\hline Pumpkin, boiled & 75 & 8 & 64 & 5 \\
\hline Milk & $250 \mathrm{~mL}$ & 12 & 32 & 4 \\
\hline Nuts & 30 & 7 & 25 & 2 \\
\hline
\end{tabular}

colonic microbial fermentation, leading to the production of short chain fatty acids that provide a direct energy source for colonic epithelium and influence hepatic insulin sensitivity. ${ }^{26}$ Fibre can be classed as soluble (viscous or non-viscous) and nonsoluble, properties that influence gastrointestinal absorption and metabolic effects. Viscous fibres such as vegetable gums and those derived from fruits, legumes, and psyllium slow down digestion and reduce postprandial glycaemia and cholesterol absorption, whereas insoluble fibres (eg, from wheat bran) have limited metabolic actions.

\section{Added and free sugar}

Added sugars are defined as sugars that are added to foods during food processing, manufacturing, or preparation. The newer term, "free sugars," also includes sugars naturally present in unsweetened fruit juices: otherwise, these two terms are interchangeable. Under this definition, only lactose naturally present in milk products and sugars contained within the cellular structure of foods (eg, whole fruits) would be excluded. ${ }^{27}$

Most health authorities agree that overconsumption of added sugars, and particularly sugar sweetened drinks, has contributed to the obesity epidemic. ${ }^{27}$ In the higher quality prospective observational studies, changes in consumption of sugary drinks are directly associated with changes in energy intake ${ }^{28}$ and body weight. ${ }^{29}$ Furthermore, two large randomised controlled trials found that elimination of sugary drinks reduced body weight among adolescents at one year ${ }^{30}$ and among younger children at 18 months. ${ }^{31}$ In metaanalyses of trials in adults consuming unrestricted diets, reduced intake of added sugars is associated with a modest decrease in body weight, while higher intake is associated with a comparable gain. Isocaloric substitution of sugars for other carbohydrate, however, did not affect body weight. ${ }^{32}$

The potential mechanisms relating sugar to weight gain remain a topic of debate. Several investigators have highlighted the potential role of fructose. ${ }^{33-39}$ Fructose is metabolised primarily in the gut and liver and, under certain experimental conditions, can stimulate de novo lipogenesis, inflammation, and insulin resistance. However, the relevance of these findings to typical consumption patterns has been questioned. ${ }^{40} 41$ Moreover, high intakes of fruits with relatively high amounts of fructose are associated with good metabolic health, suggesting that the food source of fructose is also important. ${ }^{42}$

The relative contribution of added sugar versus other carbohydrates to the obesity epidemic remains unknown. Indeed, high GL starchy foods (without fructose) contribute substantially more calories to typical Western diets than added sugar. ${ }^{43}$ In Australia, intakes of added sugars and sugar sweetened drinks have progressively declined since the 1990s, even as mean body mass index in adults and children has risen sharply. ${ }^{44}$

Beyond body weight, meta-analyses of randomised trials indicate that higher intakes of added sugars raise triglycerides, total cholesterol, blood pressure, and other risk factors for cardiovascular disease. ${ }^{38}$ fatty liver disease, an obesity related condition that has emerged as a major public health threat. Reduction of fructose ${ }^{45-47}$ Of special concern is non-alcoholic or sugar consumption in several clinical trials resulted in lower intrahepatic fat. ${ }^{48-50}$ However, each of these studies has design limitations, such as lack of a control group and confounding by unintended weight loss. In a six month trial, people consuming sugar sweetened drinks had higher levels of liver and ectopic fat than those consuming drinks without added sugar, even though body weight did not differ by diet group. ${ }^{47}$

Based on the finding that "increasing or decreasing free sugars is associated with parallel changes in body weight ... regardless of the level of intake of free sugars," the 2015 WHO guidelines recommended that consumption of free sugars should be less than $10 \%$ of energy intake for both adults and children, with potential additional benefits below $5 \%{ }^{27}$ The Scientific Advisory Committee on Nutrition in the UK recommended a 5\% upper limit, noting potential benefits at this lower level for dental health and total energy intake. ${ }^{51}$ (Modern starchy foods may also contribute to dental carries. ${ }^{52}$ ) The 2015-2020 Dietary Guidelines for Americans recommend a limit on added sugars of $10 \%$ total energy. ${ }^{53}$

\section{Composite quality indices}

Beyond the mechanisms implied by these broad classification systems, carbohydrate containing foods may influence health in various other ways. Whole plant foods contain myriad compounds with demonstrably beneficial (vitamins, minerals, and antioxidant and anti-inflammatory phytochemicals) or possibly adverse ${ }^{54}$ (lectins, phytates) actions. Ultimately, diet must be considered in an integrated fashion, with changes in consumption of one category of food affecting others. The nature of these exchanges will determine the apparent healthfulness of specific foods in population studies. Recognising this challenge, several indices for carbohydrate quality (based on GI, fibre, whole:total grain consumption, and other factors) and total diet quality have been proposed.

\section{How do carbohydrate containing foods affect health?}

Grains

Grains - the seeds of cereal grasses and similar plant families-are staple foods and a major source of dietary carbohydrate worldwide. Minimally processed whole grains retain all three components of the seed. Refined grains are processed to remove the protein and fat rich germ and fibre rich bran, leaving only the starchy endosperm. Meta-analyses of randomised clinical trials indicate that, compared with diets without them, whole grains produce small but significant reductions in low density lipoprotein (LDL) cholesterol, total 
cholesterol, and percentage body fat; they also improve postprandial glucose levels and glucose homeostasis. .5-57 $^{\text {. }}$

Prospective cohort studies have also shown significant inverse associations between whole grain intake and incidence of type 2 diabetes, coronary heart disease, ischaemic stroke, total cardiovascular disease, and several cancers, as well as risk of death from all causes. ${ }^{58-62}$ Conversely, greater refined grain intake, especially from white rice, is associated with an increased risk of type 2 diabetes. ${ }^{5963}$ Whole kernel or coarsely milled grains tend to have lower GI than refined grains and contain higher amounts of fibre and phytochemicals with potential anti-inflammatory and antioxidant properties.

However, the relative health benefits of whole grains and wholemeal foods compared with other categories of whole foods with lower carbohydrate content (eg, nuts, seeds, legumes, avocado, olives) has not been well studied. Furthermore, most whole grains in processed foods do not contain the intact whole grain kernel but have been milled into a fine particle size (thus higher GI) flour, with varying amounts of bran and germ reincorporated. Therefore, food labelled as whole grain may not have the same health benefits as intact or minimally processed whole kernel grains (wheat berries, steel cut oats, quinoa), and some whole grain foods contain high amounts of added sugar.

\section{Potatoes}

Potatoes, the leading vegetable food in most countries, are another major source of dietary carbohydrate. Although potatoes have some nutrients (such as vitamin C, potassium, and fibre), they contain predominantly starch with a high GI as typically eaten. ${ }^{14}$ In three cohorts of US men and women, increased intake of potatoes was associated with greater weight gain ${ }^{64}$ and higher risk of type 2 diabetes, even after adjustment for body mass index and other diabetes risk factors. ${ }^{65}$ In the same cohorts, higher intake of baked, boiled, or mashed potatoes and French fries was independently associated with an increased risk of developing hypertension. ${ }^{66}$ Thus, the health effects of potatoes more closely resemble those of refined grains than those of other vegetables.

\section{Legumes}

Legumes such as beans, peas, and lentils, like whole grains, improve nutritional quality and health outcomes when included in typical dietary patterns. Legumes contain low GI carbohydrate and relatively high amounts of protein, fibre, and other nutrients. ${ }^{1467}$ A meta-analysis of randomised clinical trials found a significant decrease in total and LDL cholesterol for non-soy legume dietary interventions compared with control diets. ${ }^{68}$ Another meta-analysis found a 10\% lower risk of cardiovascular disease comparing the highest with the lowest categories of consumption. ${ }^{69}$ In a Costa Rican population, increasing the ratio of beans to white rice was associated with lower cardiometabolic risk factors, including blood lipids and blood pressure. $^{70}$

\section{Fruits}

Whole fruits are high in fibre, vitamins, minerals, and phytochemicals and typically have moderate to low GL. ${ }^{14}$ Regular consumption of fruits is associated with lower risk of type 2 diabetes, cardiovascular disease, cancer, and all-cause mortality in prospective cohort studies. ${ }^{71-73}$ Greater consumption of whole fruits (especially blueberries, grapes, and apples) is significantly associated with lower risk of diabetes, whereas greater consumption of fruit juices is associated with a higher risk in three US cohorts. ${ }^{74}$ Compared with whole fruits, fruit juices tend to have less fibre, fewer micronutrients, and higher $\mathrm{GI},{ }^{75}$ and for these reasons, classifying whole fruits and juices together in dietary recommendations is controversial.

\section{What are the metabolic effects of carbohydrates in populations?}

Residents in places associated with extreme longevity have traditionally consumed high carbohydrate diets, although associated healthy lifestyle factors may confound a causal interpretation. ${ }^{76} \mathrm{By}$ contrast, the PURE study in 18 countries reported that higher carbohydrate intake was associated with increased mortality, but here too, confounding is possible (eg, many people in low income countries subsist predominantly on starchy foods such as white rice). ${ }^{778}$ In long term large cohorts studied in the US, total carbohydrate intake is also associated with higher mortality, though the type of dietary fat importantly modified risk. ${ }^{79}$ Analogously, substitution of saturated fat with low GI carbohydrate is associated with lower risk of myocardial infarction, whereas substitution with high GI carbohydrates is associated with higher risk. ${ }^{80}$

Clinical trials have shown that low carbohydrate diets produce greater weight loss than lower fat diets in the short term, but this difference diminishes with time because of poor long term compliance. ${ }^{81-85}$ The recent DIETFITs study reported a non-significant advantage for a healthy low carbohydrate versus healthy low fat diet, but both groups were counselled to limit sugar, refined grains, and processed foods in general. ${ }^{86}$ Thus evidence suggests that the type of carbohydrates may have a greater effect on health outcomes than total amount for the general population. However, specific groups may respond differently to the carbohydrate quantity and quality.

Insulin resistance, metabolic syndrome, and diabetes

The metabolic syndrome (characterised by central adiposity, hypertension, dyslipidaemia, hyperglycaemia, and chronic inflammation) contributes importantly to risk of diabetes and cardiovascular disease worldwide. An underlying cause of this syndrome is insulin resistance and the associated increase in circulating insulin levels. Since insulin resistance reflects diminished ability to promote uptake of glucose into target organs, some investigators have proposed a reduced carbohydrate diet as part of treatment. ${ }^{87}$ Observational and experimental data suggest that people with low levels of physical activity or obesity (major contributors to insulin resistance) may be especially sensitive to the adverse metabolic effects of diets high in sugar or $\mathrm{GL}^{88} 89$-perhaps explaining how Asian farming societies can maintain low adiposity and cardiovascular disease rates on white rice based diets.

People with diabetes may particularly benefit from reducing consumption of foods that increase postprandial blood glucose. Preliminary evidence suggests improved glycaemic control, lower triglycerides, and other metabolic advantages from low carbohydrate or low GI diets in both type $1^{90}$ and type 2 diabetes, ${ }^{91}$ though long term data on efficacy and safety are lacking.

\section{Early insulin secretion}

Early insulin secretion reflects the tendency of the pancreatic $\square$ cells to release insulin rapidly after carbohydrate ingestion. This clinical measure, distinct from insulin resistance, can be assessed as the blood insulin concentration 30 minutes into a standard oral glucose tolerance test (insulin 30). ${ }^{92}$ According to the carbohydrate-insulin model of obesity, people with high insulin secretion would be especially susceptible to weight gain on a high GL diet, a hypothesis with some support from laboratory, observational, and clinical research. ${ }^{93-95}$ High insulin action in adipose tissue may have an anabolic effect that promotes fat deposition, leading to increased hunger and lower energy expenditure. A recent Mendelian randomisation study found that genetically determined insulin 30 results strongly predicted body mass index. ${ }^{96}$ However, neither insulin 30 nor genetic risk was found to modify response to diet in DIETFITS, although GL was notably low in both diet groups of that study. ${ }^{86}$ 


\section{Box 1: Carbohydrate controversies}

- Would reduction in total carbohydrate intake (currently typically $45-65 \%$ of total energy) help control body weight in general population and susceptible subgroups?

- What is the role of a low carbohydrate diet in prevention and treatment of metabolic syndrome and type 2 diabetes, and in management of type 1 diabetes?

- Does ketosis induced by severe carbohydrate restriction provide any unique metabolic benefits and, if so, in what clinical settings would this diet be advisable?

- To what level should added (or free) sugars be restricted for optimum individual health and for the population as a whole?

- Would substitution of fructose in added sugars with glucose based sweeteners provide metabolic benefit or harm?

- Would substitution of free sugars with poorly digestible sugars, sugar alcohols, or artificial sweeteners provide health benefits or harms (eg, unexpected effects on the microbiome)?

- Would increased intake of resistant starch provide health benefits?

- What are the health effects of substituting whole grains with other high carbohydrate (fruits, legumes) or high fat (nuts, seeds, avocado) whole plant foods?

- What are the long term effects of different types of carbohydrates on population risk of cancer, neurodegenerative diseases, and cognitive function?

- Which carbohydrate based foods will provide an optimal combination of health benefits, environmental sustainability, cost, and public acceptability?

\section{Salivary amylase}

The diploid copy number of the salivary amylase gene (AMY1) varies widely, affecting amylase protein concentration in saliva. People with higher copy numbers have higher postprandial glycaemia after consumption of starchy (but not sugary) foods. ${ }^{97}$ High AMY1 copy number may have provided a survival advantage, but its relevance to obesity and metabolic disease today remains unclear. ${ }^{98-100}$ A recent study reported a diet-gene interaction such that the lowest body mass index was observed among people with high starch intake and low AMY1 copy number (reflecting low genetic capacity to digest starch). ${ }^{99}$

\section{Conclusions}

Although human populations have thrived on diets with widely varying macronutrient ratios, the recent influx of rapidly digestible, high GI carbohydrates in developed nations has contributed to the epidemics of obesity and cardiometabolic disease. Moreover, the traditional starch based diets of some developing nations have likely contributed to rising risk of chronic disease, with the decrease in physical activity and higher body mass index associated with rapid urbanisation.

However, carbohydrate quality seems to have a more important role in population health than carbohydrate amount. A strong case can be made for consumption of high GL grains, potato products, and added sugars (especially in drinks) being causally related to obesity, diabetes, cardiovascular disease, and some cancers; whereas nonstarchy vegetables, whole fruits, legumes, and whole kernel grains appear protective. Nevertheless, the metabolic effects of total and high GI carbohydrate may vary among individuals, depending on the degree of insulin resistance, glucose intolerance, or other inherited or acquired biological predispositions.

Despite much new knowledge about the metabolic effects of carbohydrate and areas of broad consensus, many controversies remain. Most long term data derive from observational studies, which may be affected by confounding and other methodological problems. Most randomised controlled trials are short, rely on proxy measures, lack blinding, do not control for treatment intensity between dietary groups, and have limited compliance. Additional relevant considerations in effectiveness studies include the behavioural and environmental factors (eg, food availability and affordability) affecting compliance. The resolution of these controversies (summarised in box 1) will require mechanistically oriented feeding studies and long term clinical trials, prospective observational research, and examination of economic and environmental impacts.

Contributors and sources: All authors contributed to the first draft of the manuscript and provided critical revisions. DSL is guarantor. We thank Fiona Atkinson for help with development of table 1.

Competing interests: We have read and understood BMJ policy on declaration of interests and declare the following interests: DSL received research grants (to Boston Children's Hospital) from the National Institutes of Health, Nutrition Science Initiative, the Laura and John Arnold Foundation and other philanthropic organisations unaffiliated with the food industry; and received royalties for books on obesity and nutrition that recommend a low glycaemic load diet. FBH received research support from California Walnut Commission and lecture fees from Metagenics.
LT received grants (to University of Lausanne) from the Swiss National Science Foundation from the Swiss Federal Bureau for Sport, and research support from Sorematec Italy (to Hôpital Intercantonal de la Broye) for a clinical trial related to physical activity in the treatment of patients with the metabolic syndrome; and received speakers fees from the Gatorade Sport Science Institute, Soremartec Italy, and Nestlé SA. JBM received research grants from the Australian National Health and Medical Research Council, the European Union, the Glycemic Index Foundation; and received royalties for books on nutrition that recommend a low glycaemic index diet. She oversees a glycaemic index testing service at the University of Sydney and is president and non-executive director of the Glycemic Index Foundation.

Provenance and peer review: Commissioned; externally peer reviewed.

This article is one of a series commissioned by The $B M J$. Open access fees for the series were funded by Swiss Re, which had no input into the commissioning or peer review of the articles.

David S Ludwig, professor ${ }^{123}$

Frank B Hu, professor ${ }^{34}$

Luc Tappy, professor ${ }^{5}$

Jennie Brand-Miller, professor ${ }^{6}$

${ }^{1}$ New Balance Foundation Obesity Prevention Center, Boston Children's Hospital, Boston, MA, USA

${ }^{2}$ Department of Pediatrics, Harvard Medical School, Boston, MA, USA

${ }^{3}$ Department of Nutrition, Harvard T H Chan School of Public Health, Boston, USA

${ }^{4}$ Channing Division of Network Medicine, Brigham and Women's Hospital, Harvard Medical School, Boston

${ }^{5}$ Department of Physiology, University of Lausanne, Lausanne, Switzerland.

${ }^{6}$ Charles Perkins Centre, School of Life and

Environmental Sciences, University of Sydney, Sydney, Australia

Correspondence to: D Ludwig

david.ludwig@childrens.harvard.edu

1 Håglin L. Nutrient intake among Saami people today compared with an old, traditional Saami diet. Arctic Med Res 1991;Suppl:741-6.

2 Heinbecker P. Studies on the metabolism of Eskimos. J Biol Chem 1928;80:461-75.

3 Hardy K, Brand-Miller J, Brown KD, Thomas MG, Copeland $\mathrm{L}$. The importance of dietary carbohydrate in human evolution. Q Rev Biol 2015;90:251-68. doi:10.1086/682587

4 Marlowe FW, Berbesque JC, Wood B, Crittenden A, Porter C, Mabulla A. Honey, Hadza, hunter-gatherers, and human evolution. J Hum Evol 2014;71:119-28. doi:10.1016/j.jhevol.2014.03.006

Leonard WR, Snodgrass IJ, Robertson ML. Effects of brain evolution on human nutrition and metabolism. Annu Rev Nutr 2007;27:311-27. doi:10.1146/ annurev.nutr.27.061406.093659

6 Perry GH, Dominy NJ, Claw KG, et al. Diet and the evolution of human amylase gene copy number variation. Nat Genet 2007;39:1256-60. doi:10.1038/ng2123

7 Ségurel L, Bon C. On the evolution of lactase persistence in humans. Annu Rev Genomics Hum Genet 2017:18:297-319. doi:10.1146/annurevgenom-091416-035340

8 Hujoel P. Dietary carbohydrates and dentalsystemic diseases. J Dent Res 2009;88:490-502. doi:10.1177/0022034509337700

9 Humphrey LT, De Groote I, Morales J, et al. Earliest evidence for caries and exploitation of starchy plant foods in Pleistocene huntergatherers from Morocco. Proc Natl Acad Sci U S A 2014;111:954-9. doi:10.1073/ pnas.1318176111

10 Mummert A, Esche E, Robinson J, Armelagos G). Stature and robusticity during the agricultural transition: evidence from the bioarchaeological record. Econ Hum Biol 2011:9:284-301. doi:10.1016/j.ehb.2011.03.004 
11 Crapo PA, Olefsky JM. Food fallacies and blood sugar. N Engl J Med 1983;309:44-5. doi:10.1056 NEJM198307073090109

12 Bantle JP, Laine DC, Castle GW, Thomas JW, Hoogwerf BJ, Goetz FC. Postprandial glucose and insulin responses to meals containing different carbohydrates in normal and diabetic subjects. N Engl J Med 1983;309:7-12. doi:10.1056/ NEIM198307073090102

13 Wahlqvist ML, Wilmshurst EG, Richardson EN. The effect of chain length on glucose absorption and the related metabolic response. Am J Clin Nutr 1978;31:1998-2001. doi:10.1093/ ajcn/31.11.1998

14 Atkinson FS, Foster-Powell K, Brand-Miller JC. International tables of glycemic index and glycemic load values: 2008. Diabetes Care 2008;31:2281-3. doi:10.2337/dc08-1239

15 Ley SH, Hamdy O, Mohan V Hu FB. Prevention and management of type 2 diabetes: dietary components and nutritional strategies. Lancet 2014;383:19992007. doi:10.1016/S0140-6736(14)60613-9

16 Mente A, de Koning L, Shannon HS, Anand SS. A systematic review of the evidence supporting a causal link between dietary factors and coronary heart disease. Arch Intern Med 2009;169:659-69. doi:10.1001/archinternmed.2009.38

17 Ludwig DS. The glycemic index: physiological mechanisms relating to obesity, diabetes, and cardiovascular disease. JAMA 2002;287:2414-23. doi:10.1001/jama.287.18.2414

18 Bao J, Atkinson F, Petocz P, Willett WC, Brand Miller JC. Prediction of postprandial glycemia and insulinemia in lean, young, healthy adults: glycemic load compared with carbohydrate content alone. Am J Clin Nutr 2011;93:984-96. doi:10.3945/ ajcn.110.005033

19 Livesey G, Taylor R, Livesey H, Liu S. Is there a dose-response relation of dietary glycemic load to risk of type 2 diabetes? Meta-analysis of prospective cohort studies. Am J Clin Nutr 2013;97:584-96. doi:10.3945/ajcn.112.041467

20 Dong JY, Zhang YH, Wang P, Qin LQ. Meta-analysis of dietary glycemic load and glycemic index in relation to risk of coronary heart disease. $\mathrm{Am}$ J Cardiol 2012;109:1608-13. doi:10.1016/j. amjcard.2012.01.385

21 Fan J, Song Y, Wang Y, Hui R, Zhang W. Dietary glycemic index, glycemic load, and risk of coronary heart disease, stroke, and stroke mortality: systematic review with meta-analysis. PLOS One 2012;7:e52182. doi:10.1371/journal. pone.0052182

22 Mirrahimi A, de Souza RJ, Chiavaroli L, et al. Associations of glycemic index and load with coronary heart disease events: a systematic review and meta-analysis of prospective cohorts. / Am Heart Assoc 2012;1:e000752. doi:10.1161/ JAHA.112.000752

23 Dong JY, Qin LQ. Dietary glycemic index, glycemic load, and risk of breast cancer: meta-analysis of prospective cohort studies. Breast Cancer Res Treat 2011;126:287-94. doi:10.1007/s10549011-1343-3

24 Gnagnarella P, Gandini S, La Vecchia C, Maisonneuve P. Glycemic index, glycemic load, and cancer risk: a meta-analysis. Am J Clin Nutr 2008;87:1793-801. doi:10.1093/ ajcn/87.6.1793

25 Kristo AS, Matthan NR, Lichtenstein AH. Effect of diets differing in glycemic index and glycemic load on cardiovascular risk factors: review of randomized controlled-feeding trials. Nutrients 2013;5:1071-80. doi:10.3390/nu5041071

26 Bach Knudsen KE. Microbial degradation of wholegrain complex carbohydrates and impact on shortchain fatty acids and health. Adv Nutr 2015;6 206-13. doi:10.3945/an.114.007450

27 WHO. Sugars intake for adults and children: Guideline. WHO, 2015.

28 Vartanian LR, Schwartz MB, Brownell KD. Effects of soft drink consumption on nutrition and health: a systematic review and meta-analysis. Am Public Health 2007:97:667-75. doi:10.2105/ AJPH.2005.083782
29 Malik VS, Pan A, Willett WC, Hu FB. Sugar-sweetened beverages and weight gain in children and adults: a systematic review and meta-analysis. Am J Clin Nutr 2013;98:1084-102. doi:10.3945/ ajcn.113.058362

30 Ebbeling CB, Feldman HA, Chomitz VR, et al. A randomized trial of sugar-sweetened beverages and adolescent body weight. $N$ Engl I Med 2012;367:1407-16. doi:10.1056/ NEJMoa1203388

31 de Ruyter JC, Olthof MR, Seidell JC, Katan MB. A trial of sugar-free or sugar-sweetened beverages and body weight in children. N Engl / Med 2012;367:1397406. doi:10.1056/NEJMoa1203034

32 Te Morenga L, Mallard S, Mann J. Dietary sugars and body weight: systematic review and metaanalyses of randomised controlled trials and cohort studies. BMJ 2012;346:e7492. doi:10.1136/bmj. e7492

33 Bray GA. Soft drink consumption and obesity: it is all about fructose. Curr Opin Lipidol 2010;21:51-7. doi:10.1097/MOL.0b013e3283346ca2

34 Campos VC, Tappy L. Physiological handling of dietary fructose-containing sugars: implications for health. Int J Obes (Lond) 2016;40(Suppl 1):S6-11. doi:10.1038/ijo.2016.8

35 DiNicolantonio JJ, Mehta V, Onkaramurthy N, O'Keefe JH. Fructose-induced inflammation and increased cortisol: A new mechanism for how sugar induces visceral adiposity. Prog Cardiovasc Dis 2017 Dec 8:S0033-0620(17)30162-7. [Epub ahead of print]. doi:10.1016/j.pcad.2017.12.001

36 Goran MI, Dumke K, Bouret SG, Kayser B, Walker RW, Blumberg B. The obesogenic effect of high fructose exposure during early development. Nat Rev Endocrinol 2013;9:494-500. doi:10.1038/ nrendo.2013.108

37 Lustig RH, Schmidt LA, Brindis CD. Public health The toxic truth about sugar. Nature 2012;482:27-9. doi:10.1038/482027a

38 Malik VS, Hu FB. Fructose and Cardiometabolic Health: What the Evidence From Sugar-Sweetened Beverages Tells Us. I Am Coll Cardiol 2015;66: 1615-24. doi:10.1016/j.jacc.2015.08.025

39 Stanhope KL. Role of fructose-containing sugars in the epidemics of obesity and metabolic syndrome. Annu Rev Med 2012;63:329-43. doi:10.1146 annurev-med-042010-113026

40 Sievenpiper JL, de Souza RJ, Mirrahimi A, et al. Effect of fructose on body weight in controlled feeding trials: a systematic review and meta-analysis. Ann Intern Med 2012;156:291-304. doi:10.7326/ 0003-4819-156-4-201202210-00007

41 White JS. Challenging the fructose hypothesis: new perspectives on fructose consumption and metabolism. Adv Nutr 2013;4:246-56. doi:10.3945/ an.112.003137

42 Ludwig DS. Examining the health effects of fructose. JAMA 2013;310:33-4. doi:10.1001/ jama.2013.6562

43 JFWE Consultation. Carbohydrates in human nutrition. (FAO Food and Nutrition Paper 66). Rome, 1997.

44 Brand-Miller JC, Barclay AW. Declining consumption of added sugars and sugar-sweetened beverages in Australia: a challenge for obesity prevention. Am J Clin Nutr 2017;105:854-63. doi:10.3945/ ajcn.116.145318

45 Stanhope KL, Medici V, Bremer AA, et al. A dose response study of consuming high-fructose corn syrup-sweetened beverages on lipid/lipoprotein risk factors for cardiovascular disease in young adults. Am J Clin Nutr 2015;101:1144-54. doi:10.3945/ ajcn.114.100461

46 Te Morenga LA, Howatson AJ, Jones RM, Mann J. Dietary sugars and cardiometabolic risk: systematic review and meta-analyses of randomized controlled trials of the effects on blood pressure and lipids. Am J Clin Nutr 2014;100:65-79. doi:10.3945/ ajcn.113.081521

47 Maersk M, Belza A, Stødkilde- ørgensen H, et al. Sucrose-sweetened beverages increase fat storage in the liver, muscle, and visceral fat depot: a 6-mo randomized intervention study. Am / Clin Nutr 2012;95:283-9. doi:10.3945/ ajcn.111.022533
48 Campos V, Despland C, Brandejsky V, et al. Sugarand artificially sweetened beverages and intrahepatic fat: A randomized controlled trial. Obesity (Silver Spring) 2015;23:2335-9. doi:10.1002/oby.21310.

49 Schwarz JM, Noworolski SM, Erkin-Cakmak A, et al. Effects of Dietary Fructose Restriction on Liver Fat, De Novo Lipogenesis, and Insulin Kinetics in Children With Obesity. Gastroenterology 2017;153:743-52. doi:10.1053/i.gastro.2017.05.043.

50 Ibarra-Reynoso LDR, López-Lemus HL, GaraySevilla ME, Malacara JM. Effect of Restriction of Foods with High Fructose Corn Syrup Content on Metabolic Indices and Fatty Liver in Obese Children. Obes Facts 2017;10:332-40. doi:10.1159/000476069.

51 Public Health England. Carbohydrates and health. Scientific Advisory Committee on Nutrition, 2015.

52 Lingström P, van Houte J, Kashket S. Food starches and dental caries. Crit Rev Oral Biol Med 2000;11:366-80. doi:10.1177/10454411000 110030601

53 US Department of Health and Human Services, US Department of Agriculture. 2015-2020 dietary guidelines for Americans. 8th ed. DHHS, 2015.

54 Vasconcelos IM, Oliveira JT. Antinutritional properties of plant lectins. Toxicon 2004;44:385-403. doi:10.1016/j.toxicon.2004.05.005

55 Hollænder PL, Ross AB, Kristensen M. Whole-grain and blood lipid changes in apparently healthy adults: a systematic review and meta-analysis of randomized controlled studies. Am J Clin Nutr 2015;102:556-72. doi:10.3945/ajcn.115.109165

56 Marventano S, Vetrani C, Vitale M, Godos J, Riccardi G, Grosso G. Whole grain intake and glycaemic control in healthy subjects: a systematic review and meta-analysis of randomized controlled trials. Nutrients 2017:9:E769. doi:10.3390/ nu9070769

57 Pol K, Christensen R, Bartels EM, Raben A, Tetens I, Kristensen $\mathrm{M}$. Whole grain and body weight changes in apparently healthy adults: a systematic review and meta-analysis of randomized controlled studies. Am J Clin Nutr 2013;98:872-84. doi:10.3945/ ajcn.113.064659

58 Aune D, Keum N, Giovannucci E, et al. Whole grain consumption and risk of cardiovascular disease, cancer, and all cause and cause specific mortality: systematic review and dose-response meta-analysis of prospective studies. BMJ 2016;353:i2716. doi:10.1136/bmj.i2716

59 Aune D, Norat T, Romundstad P, Vatten LJ. Whole grain and refined grain consumption and the risk of type 2 diabetes: a systematic review and doseresponse meta-analysis of cohort studies. Eur 1 Epidemiol 2013;28:845-58. doi:10.1007/s10654013-9852-5

60 Chen J, Huang Q, Shi W, Yang L, Chen J, Lan Q. Meta-Analysis of the Association Between Whole and Refined Grain Consumption and Stroke Risk Based on Prospective Cohort Studies. Asia Pac J Public Health 2016:28:563-75. doi:10.1177/1010539516650722

61 Tang G, Wang D, Long J, Yang F, Si L. Metaanalysis of the association between whole grain intake and coronary heart disease risk Am J Cardiol 2015;115:625-9. doi:10.1016/j. amjcard.2014.12.015

62 Zong G, Gao A, Hu FB, Sun Q. Whole Grain Intake and Mortality From All Causes, Cardiovascular Disease, and Cancer: A Meta-Analysis of Prospective Cohort Studies. Circulation 2016;133:2370-80. doi:10.1161/CIRCULATIONAHA.115.021101

63 Hu EA, Pan A, Malik V, Sun Q. White rice consumption and risk of type 2 diabetes: meta-analysis and systematic review. BMJ 2012:344:e1454 doi:10.1136/bmj.e1454. doi:10.1136/bmj.e1454

64 Mozaffarian D, Hao T, Rimm EB, Willett WC, $\mathrm{Hu}$ FB. Changes in diet and lifestyle and longterm weight gain in women and men. $N$ Engl J Med 2011;364:2392-404. doi:10.1056/ NEJMoa1014296

65 Muraki I, Rimm EB, Willett WC, Manson JE, Hu FB, Sun Q. Potato Consumption and Risk of Type 2 Diabetes: Results From Three Prospective Cohort Studies. Diabetes Care 2016;39:376-84 doi:10.2337/dc15-0547 
66 Borgi L, Rimm EB, Willett WC, Forman JP. Potato intake and incidence of hypertension: results from three prospective US cohort studies. BMJ 2016;353:i2351. doi:10.1136/bmj.i2351

67 Mattei J, Malik V, Wedick NM, et al, Global Nutrition Epidemiologic Transition Initiative. Reducing the global burden of type 2 diabetes by improving the quality of staple foods: The Global Nutrition and Epidemiologic Transition Initiative. Global Health 2015;11:23. doi:10.1186/s12992-0150109-9

68 Bazzano LA, Thompson AM, Tees MT, Nguyen CH, Winham DM. Non-soy legume consumption lowers cholesterol levels: a meta-analysis of randomized controlled trials. Nutr Metab Cardiovasc Dis 2011;21:94-103. doi:10.1016/j. numecd.2009.08.012

69 Marventano S, Izquierdo Pulido M, SánchezGonzález C, et al. Legume consumption and CVD risk: a systematic review and meta-analysis. Public Health Nutr 2017;20:245-54. doi:10.1017/ S1368980016002299

70 Mattei J. Hu FB, Campos H. A higher ratio of beans to white rice is associated with lower cardiometabolic risk factors in Costa Rican adults. Am J Clin Nutr 2011;94:869-76. doi:10.3945/ ajcn.111.013219

71 Aune D, Giovannucci E, Boffetta P, et al. Fruit and vegetable intake and the risk of cardiovascular disease, total cancer and all-cause mortality-a systematic review and dose-response meta-analysis of prospective studies. Int J Epidemiol 2017;46:1029-56. doi:10.1093/ije/ dyw319

72 Wang PY, Fang JC, Gao ZH, Zhang C, Xie SY. Higher intake of fruits, vegetables or their fiber reduces the risk of type 2 diabetes: A meta-analysis. J Diabetes Investig 2016;7:56-69. doi:10.1111/jdi.12376

73 Du H, Li L, Bennett D, et al, China Kadoorie Biobank Study. Fresh Fruit Consumption and Major Cardiovascular Disease in China. N Engl J Med 2016;374:1332-43. doi:10.1056/ NEIMoa1501451

74 Muraki I, Imamura F, Manson JE, et al. Fruit consumption and risk of type 2 diabetes: results from three prospective longitudinal cohort studies. BM/ 2013:347:f5001. doi:10.1136/bmj.f5001

75 Hu FB, Malik VS. Sugar-sweetened beverages and risk of obesity and type 2 diabetes: epidemiologic evidence. Physiol Behav 2010;100:47-54. doi:10.1016/j.physbeh.2010.01.036

76 Buettner D. The blue zones: lessons for living longer from the people who've lived the longest. National Geographic Society, 2008.

77 Dehghan M, Mente A, Zhang X, et al, Prospective Urban Rural Epidemiology (PURE) study investigators. Associations of fats and carbohydrate intake with cardiovascular disease and mortality in 18 countries from five continents (PURE): a prospective cohort study. Lancet 2017;390:2050-62. doi:10.1016/ S0140-6736(17)32252-3
78 Pan A, Lin X, Hemler E, Hu FB. Diet and cardiovascular disease: advances and challenges in populationbased studies. Cell Metab 2018;27:489-96. doi:10.1016/j.cmet.2018.02.017

79 Wang DD, Li Y, Chiuve SE, et al. Association of specific dietary fats with total and cause-specific mortality. JAMA Intern Med 2016;176:1134-45. doi:10.1001/ jamainternmed.2016.2417

80 Jakobsen MU, Dethlefsen C, Joensen AM, et al. Intake of carbohydrates compared with intake of saturated fatty acids and risk of myocardial infarction: importance of the glycemic index. Am J Clin Nutr 2010;91:1764-8. doi:10.3945/ ajcn.2009.29099

81 Bueno NB, de Melo IS, de Oliveira SL, da Rocha Ataide T. Very-low-carbohydrate ketogenic diet v. low-fat diet for long-term weight loss: a meta-analysis of randomised controlled trials. Br J Nutr 2013;110:1178-87. doi:10.1017/ S0007114513000548

82 Mancini JG, Filion KB, Atallah R, Eisenberg MJ. Systematic review of the Mediterranean diet for long term weight loss. Am / Med 2016:129:407-415.e4. doi:10.1016/j.amjmed.2015.11.028.

83 Mansoor N, Vinknes KJ, Veierød MB, Retterstøl K. Effects of low-carbohydrate diets $v$. low-fat diets on body weight and cardiovascular risk factors: a meta-analysis of randomised controlled trials. Br J Nutr 2016;115:466-79. doi:10.1017/ S0007114515004699

84 Sackner-Bernstein J, Kanter D, Kaul S. Dietary intervention for overweight and obese adults: comparison of low-carbohydrate and low-fat diets. a meta-analysis. PLoS One 2015;10:e0139817. doi:10.1371/journal.pone.0139817

85 Tobias DK, Chen M, Manson JE, Ludwig DS, Willett W, Hu FB. Effect of low-fat diet interventions versus other diet interventions on long-term weight change in adults: a systematic review and meta-analysis. Lancet Diabetes Endocrinol 2015:3.968-79. doi:10.1016/S2213-8587(15)00367-8

86 Gardner CD, Trepanowski JF, Del Gobbo LC, et al. Effect of low-fat vs low-carbohydrate diet on 12-month weight loss in overweight adults and the association with genotype pattern or insulin secretion: the DIETFITS randomized clinical trial. JAMA 2018:319:667-79. doi:10.1001/ jama.2018.0245

87 Volek JS, Fernandez ML, Feinman RD, Phinney SD. Dietary carbohydrate restriction induces a unique metabolic state positively affecting atherogenic dyslipidemia, fatty acid partitioning, and metabolic syndrome. Prog Lipid Res 2008;47:307-18. doi:10.1016/i.plipres.2008.02.003

88 Bidwell AJ, Fairchild TJ, Redmond J, Wang L, Keslacy S, Kanaley JA. Physical activity offsets the negative effects of a high-fructose diet. Med Sci Sports Exerc 2014;46:2091-8. doi:10.1249/ MSS.0000000000000343

89 Bidwell AJ, Fairchild TJ, Wang L, Keslacy S, Kanaley JA. Effect of increased physical activity on fructose- induced glycemic response in healthy individuals. Eur J Clin Nutr 2014;68:1048-54. doi:10.1038/ ejcn.2014.90

90 Lennerz BS, Barton A, Bernstein RK, et al. Management of type 1 diabetes with a very lowcarbohydrate diet. Pediatrics 2018; e20173349 (forthcoming). doi:10.1542/peds.2017-3349

91 Feinman RD, Pogozelski WK, Astrup A, et al. Dietary carbohydrate restriction as the first approach in diabetes management: critical review and evidence base. Nutrition 2015;31:1-13. doi:10.1016/j. nut.2014.06.011

92 Chiu KC, Martinez DS, Yoon C, Chuang LM Relative contribution of insulin sensitivity and beta-cell function to plasma glucose and insulin concentrations during the oral glucose tolerance test. Metabolism 2002;51:115-20. doi:10.1053/ meta.2002.29027

93 Chaput JP, Tremblay A, Rimm EB, Bouchard C, Ludwig DS. A novel interaction between dietary composition and insulin secretion: effects on weight gain in the Quebec Family Study. Am J Clin Nutr 2008;87:303-9. doi:10.1093/ajcn/87.2.303

94 Ebbeling CB, Leidig MM, Feldman HA, Lovesky MM, Ludwig DS. Effects of a low-glycemic load vs low-fat diet in obese young adults: a randomized trial. JAMA 2007;297:2092-102. doi:10.1001/ jama.297.19.2092

95 Pawlak DB, Kushner JA, Ludwig DS. Effects of dietary glycaemic index on adiposity, glucose homoeostasis, and plasma lipids in animals. Lancet 2004;364: 778-85. doi:10.1016/S0140-6736(04)16937-7

96 Astley CM, Todd JN, Salem RM, et al. Genetic evidence that carbohydrate-stimulated insulin secretion leads to obesity. Clin Chem 2018;64:192-200. doi:10.1373/clinchem.2017.280727

97 Atkinson FS, Hancock D, Petocz P, et al. Physiological significance of higher amy1 gene copy number on postprandial responses to starchy foods in caucasian adults. Journal of Nutrition \& Intermediary Metabolism 2014;1:1510.1016/j. jnim.2014.10.044

98 Falchi M, El-Sayed Moustafa JS, Takousis P, et al. Low copy number of the salivary amylase gene predisposes to obesity. Nat Genet 2014;46:492-7. doi:10.1038/ng.2939

99 Rukh G, Ericson U, Andersson-Assarsson J, OrhoMelander M, Sonestedt E. Dietary starch intake modifies the relation between copy number variation in the salivary amylase gene and BMI Am J Clin Nutr 2017;106:256-62. doi:10.3945/ ajcn.116.149831

100 Usher CL, Handsaker RE, Esko T, et al. Structural forms of the human amylase locus and their relationships to SNPs, haplotypes and obesity. Nat Genet 2015;47:921-5. doi:10.1038/ng.3340

Cite this as: $B M J$ 2018;361:j2340 http://dx.doi.org/10.1136/bmj.j2340

\section{6 \\ OPEN ACCESS}

This is an Open Access article distributed in accordance with the terms of the Creative Commons Attribution (CC BY 4.0) license, which permits others to distribute, remix, adapt and build upon this work, for commercial use, provided the original work is properly cited. See: http:// creativecommons.org/licenses/by/4.0/ 